\section{THU0174 CHARACTERIZATION OF REMISSION IN PATIENTS WITH RHEUMATOID ARTHRITIS TREATED WITH UPADACITINIB OR COMPARATORS}

Stephen Hall ${ }^{1}$, Tsutomu Takeuchi ${ }^{2}$, Glen Thomson ${ }^{3}$, Paul Emery ${ }^{4}$, Bernard Combe $^{5}$, Andrea Everding ${ }^{6}$, Karel Pavelka ${ }^{7}$, Yanna Song ${ }^{8}$, Tim Shaw ${ }^{8}$, Alan Friedman ${ }^{8}$, In-Ho Song ${ }^{8}$, Eduardo Mysler ${ }^{9}{ }^{1}$ Monash Univ, Cabrini Health and Emeritus Research, Malvern, Australia; ${ }^{2}$ Keio Univ School of Medicine, Tokyo, Japan; ${ }^{3}$ CIADS Research, Winnipeg, Canada; ${ }^{4}$ Leeds Inst of Rheumatic and Musculoskeletal Medicine, Leeds NIHR BRC, Leeds, United Kingdom, ${ }^{5} \mathrm{CHU}$ Montpellier, Univ Montpellier, Montpellier, France; ${ }^{6} \mathrm{HRF}$ Hamburger Rheuma Forschungszentrum, Hamburg, Germany; ${ }^{7}$ Charles Univ, Prague, Czech Republic ${ }^{8}$ AbbVie Inc, North Chicago, United States of America; ${ }^{9}$ Organización Medica de Investigación, Buenos Aires, Argentina

Background: Across all phase 3 studies, treatment with upadacitinib (UPA), a JAK1-selective inhibitor, was associated with significantly higher remission (REM) rates, compared to placebo (PBO) or active comparators, in RA patients (pts) who were methotrexate (MTX)-naive, had inadequate response to conventional synthetic (csDMARD-IR) or had inadequate response or intolerance to biologic DMARDs (bDMARD-IR) Objectives: REM definitions are based on composite scores of various individual assessments of disease activity. To determine the response to UPA on REM and component assessments, we assessed the proportions of pts achieving REM using multiple REM definitions, and the improvement in their respective individual components, compared to PBO or active comparators, in 3 different RA pt populations spanning a range of RA pt populations. Methods: Three phase 3 studies included pts who were MTX naïve (SELECT EARLY, $\mathrm{n}=945$ ), MTX-IR (SELECT COMPARE, $\mathrm{n}=1629$ ) and bDMARD-IR (SELECT BEYOND, $\mathrm{n}=498$ ). The proportion of $\mathrm{pts}$ achieving REM at Week (Wk) 12 by 4 definitions (DAS28-CRP<2.6; CDAI $\leq 2.8$; SDAl $\leq 3.3$ and Boolean, defined as $\leq 1$ for TJC, SJC, patient's global assessment of disease activity [PtGA], and CRP $\leq 1 \mathrm{mg} / \mathrm{L}$ ) were determined. For each definition of REM, the mean change in each of the respective component scores was also assessed. Binary endpoints are based on Non-responder imputation (NRI), and continuous endpoints on mixed-effect model repeat measurement (MMRM). Comparisons were made between UPA-treated groups vs respective control arms (MTX, adalimumab [ADA] or PBO).

Results: Pt demographics and disease characteristics have been previously reported. ${ }^{1-3}$ At 12 wks, in EARLY and COMPARE, a significantly greater proportion of pts receiving UPA $15 \mathrm{mg}$ or $30 \mathrm{mg}$ QD achieved REM by all 4 definitions vs MTX, PBO or ADA (Table). In BEYOND, (a refractory population many of whom had inadequate response to multiple bDMARDs), a significantly greater proportion of pts receiving UPA $30 \mathrm{mg}$ achieved all REM definitions vs PBO within the first 12 wks, with significantly greater proportions on UPA $15 \mathrm{mg}$ achieving DAS28-CRP $<2.6$ and Boolean REM (Table). Rates of REM in BEYOND further increased through Wk 24 for both dose groups. ${ }^{1}$ Compared to respective control groups, pts receiving UPA 15 or $30 \mathrm{mg}$ QD had significantly greater improvements in each REM disease component (except for PhGA vs ADA in COMPARE). Significantly more pts receiving UPA also achieved the required cutoffs on the individual components of Boolean REM compared to respective controls. Conclusion: Significantly greater proportions of pts receiving UPA 15 or $30 \mathrm{mg}$ achieved REM by multiple definitions at 12 wks compared to PBO, MTX or ADA. All disease activity components of each REM definition were significantly improved in pts receiving UPA compared to MTX or $\mathrm{PBO}$, and all Boolean components were significantly improved in pts receiving UPA $15 \mathrm{mg}$ compared to ADA.

\section{REFERENCES :}

[1] Genovese, et al. 2018;Lancet.18;31116-4.

[2] van Vollenhoven R, et al. Arthritis Rheumatol. 2018;70 (supp10).

[3] Fleischmann, et al. Arthritis Rheumatol. 2018;70 (supp10).

Acknowledgement: AbbVie, Inc was the study sponsor, contributed to study design, data collection, analysis \& interpretation, and to writing, reviewing, and approval of final version. Medical writing support was provided by Naina Barretto, $\mathrm{PhD}$, of AbbVie, Inc.

Disclosure of Interests: Stephen Hall Grant/research support from: AbbVie Inc, BMS, Lilly, Janssen, Pfizer, UCB, and Novartis, Consultant for: AbbVie Inc, BMS, Lilly, Janssen, Pfizer, UCB, and Novartis, Tsutomu Takeuchi Grant/research support from: Astellas Pharma Inc, Chugai Pharmaceutical Co, Ltd., Daiichi Sankyo Co., Ltd., Takeda Pharmaceutical Co., Ltd., AbbVie GK, Asahikasei Pharma Corp., Mitsubishi Tanabe Pharma Co., Pfizer Japan Inc., Eisai Co., Ltd., AYUMI Pharmaceutical Corporation, Nipponkayaku Co. Ltd., Novartis Pharma K.K., Grant/research support from: AbbVie, Asahi Kasei, Astellas, AstraZeneca, AYUMI, Bristol-Myers Squibb, Chugai, Daiichi Sankyo, Eisai, Eli Lilly Japan, Janssen, Mitsubishi Tanabe, Nippon Kayaku, Novartis, Pfizer Japan Inc, Taiho, Taisho Toyama, Takeda, Teijin, Grant/ research support from: Astellas Pharma Inc., Bristol Myers Squibb, Chugai Pharmaceutical Co., Ltd., Mitsubishi Tanabe Pharma Co., Pfizer Japan Inc. Santen Pharmaceutical Co., Ltd., Takeda Pharmaceutical Co., Ltd., Teijin Pharma Ltd., AbbVie GK, Asahi Kasei Pharma Corp., Taisho Toyama Pharmaceutical Co., Ltd., SymBio Pharmaceuticals Ltd., Janssen Pharmaceutical K.K., Celltrion Inc., Nipponkayaku Co. Ltd., and UCB Japan, Consultant for: Astra Zeneca K.K., Eli Lilly Japan K.K., Novartis Pharma K.K., Mitsubishi Tanabe Pharma Co., Abbivie GK, Nipponkayaku Co.Ltd, Janssen Pharmaceutical K.K., Astellas Pharma Inc., Taiho Pharmaceutical Co. Ltd., Chugai Pharmaceutical Co. Ltd., Taisho Toyama Pharmaceutical Co. Ltd. GlaxoSmithKline K.K., UCB Japan Co. Ltd., Consultant for: AbbVie, Asahi Kasei, Astellas, AstraZeneca, AYUMI, Bristol-Myers Squibb, Chugai, Daiichi Sankyo, Eisai, Eli Lilly Japan, Janssen, Mitsubishi Tanabe, Nippon Kayaku, Novartis, Pfizer Japan Inc, Taiho, Taisho Toyama, Takeda, Teijin, Consultant for: Astra Zeneca K.K., Eli Lilly Japan K.K., Novartis Pharma K.K., Mitsubishi Tanabe Pharma Co., Asahi Kasei Medical K.K., AbbVie GK, Daiichi Sankyo Co., Ltd., Bristol Myers Squibb, and Nipponkayaku Co. Ltd., Speakers bureau: Astellas Pharma Inc., Bristol Myers Squibb, Chugai Pharmaceutical Co., Ltd., Mitsubishi Tanabe Pharma Co., Pfizer Japan Inc., Santen Pharmaceutical Co., Ltd., Takeda Pharmaceutical Co., Ltd., Teijin Pharma Ltd., AbbVie GK, Asahi Kasei Pharma Corp., Taisho Toyama Pharmaceutical Co., Ltd., SymBio Pharmaceuticals Ltd., Janssen Pharmaceutical K.K., Celltrion Inc., Nipponkayaku Co. Ltd., and UCB Japan, Speakers bureau: AbbVie, Asahi Kasei, Astellas, AstraZeneca, AYUMI, Bristol-Myers Squibb, Chugai, Daiichi Sankyo, Eisai, Eli Lilly Japan, Janssen, Mitsubishi Tanabe, Nippon Kayaku, Novartis, Pfizer Japan Inc, Taiho, Taisho Toyama, Takeda, Teijin, Speakers bureau: AbbVie GK., Bristol-Myers K.K., Chugai Pharmaceutical Co. Ltd., Mitsubishi Tanabe Pharma Co., Pfizer Japan Inc., Astellas Pharma Inc, Diaichi Sankyo Co. Ltd., Eisai Co. Ltd., Sanofi K.K., Teijin Pharma Ltd., Takeda Pharmaceutical Co. Ltd., Novartis Pharma K.K., Glen Thomson Grant/research support from: AbbVie, Consultant for: Amgen, Paul Emery Grant/research support from: Pfizer, MSD, AbbVie, Bristol-Myers Squibb, Roche, Consultant for: Pfizer, MSD, AbbVie, Bristol-Myers Squibb, UCB, Roche, Novartis, Gilead,Samsung, Sandoz and Lilly, Bernard Combe Consultant for: Abbvie, Bristol-Myers Squibb, Gilead, Janssen, Eli Lilly, MSD Novartis, Pfizer, Roche-Chugai, Sanofi, UCB, Andrea Everding: None declared, Karel Pavelka: None declared, Yanna Song Shareholder of: AbbVie, Employee of: AbbVie, Tim Shaw Shareholder of: AbbVie Inc, Employee of: AbbVie Inc, Alan Friedman Shareholder of: AbbVie, Employee of: AbbVie, In-Ho Song Shareholder of: AbbVie Inc, Employee of: AbbVie Inc, Eduardo Mysler Grant/research support from: AbbVie, Bristol-Myers Squibb, Eli Lilly, Pfizer, Novartis, Janssen, Grant/research support from: AbbVie, Bristol-Myers Squibb, Eli Lily, Janssen, Medimmune, Pfizer Inc, and Roche Consultant for: AbbVie, Bristol-Myers Squibb, Eli Lily, Janssen, Medimmune, Pfizer Inc, and Roche, Speakers bureau: AbbVie, Bristol-Myers Squibb, El Lilly, Pfizer, Novartis, Janssen, Speakers bureau: AbbVie, Bristol-Myers Squibb, Eli Lily, Janssen, Medimmune, Pfizer Inc, and Roche

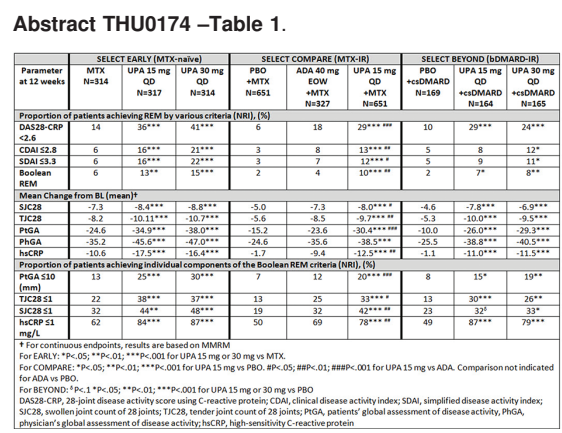

DOI: 10.1136/annrheumdis-2019-eular.2003

\section{THU0175 DOSE-DEPENDENT RISK OF METHOTREXATE FOR RENAL IMPAIRMENT IN PATIENTS WITH RHEUMATOID ARTHRITIS}

Keigo Hayashi, Kenei Sada, Yosuke Asano, Sumie Hiramatsu Asano, Yuriko Yamamura, Keiji Ohashi, Michiko Morishita, Haruki Watanabe,

Mariko Narazaki, Yoshinori Matsumoto, Tomoko Kawabata, Jun Wada. Okayama University Graduate School of Medicine, Dentistry and Pharmaceutical Sciences, Department of Nephrology, Rheumatology, Endocrinology and Metabolism, Okayama, Japan

Background: Methotrexate (MTX) is a mainstay in the therapy of rheumatoid arthritis (RA). It is recommended that MTX should be rapidly 
escalated to the maximum tolerated dose (16 - $30 \mathrm{mg} /$ week) and tapering MTX can be considered after a persistent remission ${ }^{1)}$. Renal impairment is one of the major concerns in treatment with high dose MTX for malignancy, but it is still unclear whether low dose MTX administration in RA cause the renal impairment or not.

Objectives: The purpose of this study is to elucidate the association between MTX dosage and a one-year change of estimate glomerular filtration rate (eGFR) in RA patients.

Methods: Of outpatients with RA in Okayama university hospital between 2006 and 2017, 497 patients who had continued the administration of MTX for more than one year were enrolled. All patients fulfilled the ACR/EULAR 2010 Classification Criteria for RA. Patients who had nephrotic syndrome, unilateral kidney or other rheumatic disorders other than secondary Sjögren's syndrome were excluded. The primary outcome was the change of eGFR during the most recent one year in each patient. The revised Japanese equation of Modification of Diet in Renal Disease ${ }^{2)}$ was used to calculate eGFR. MTX dosage was defined as an average dosage of MTX during the observational period. We evaluated the association between MTX dosage and the primary outcome using univariate and multivariate analysis. Results: Median (IQR) age was 64 (54 - 72) years, 78\% were female, and median disease duration was $73(31$ - 160) months. The median dosage of MTX was $8 \mathrm{mg} /$ week $(6-10.1)$ and biological agents were used in $28 \%$ of the patients. The eGFR (mean $\pm \mathrm{SD}$ ) decreased by $1.2 \pm 8.3 \mathrm{ml} / \mathrm{min} /$ $1.73 \mathrm{~m} 2$ in one year and MTX dosage was associated with the change of eGFR significant inversely $(p<0.0001)$. The eGFR in patients treated with MTX $<8 \mathrm{mg} /$ week $(\mathrm{n}=185), \geq 8$ and $<10 \quad(\mathrm{n}=131), \geq 10$ and $<12(\mathrm{n}=86)$, $\geq 12(\mathrm{n}=95)$ decreased $0.2 \pm 0.6,0.6 \pm 0.7,1.0 \pm 0.9$, and $4.6 \pm 0.8 \mathrm{ml} /$ $\mathrm{min} / 1.73 \mathrm{~m} 2 /$ year, respectively. After adjusting possible confounding factors such as sex, age, concomitant use of NSAIDs, hypertension, and $\mathrm{C}$ reactive protein (CRP) using multiple linear regression analysis, MTX dosage was still an independent risk factor for the decrease of eGFR (beta-coefficient: $0.4,95 \%$ confidence interval $-0.12-0.61, p=0.003)$.

Conclusion: Careful monitoring of renal function should be required in long-time treatment for RA patients with MTX.

\section{REFERENCES:}

[1] Smolen JS, et al. Ann Rheum Dis. 2017;76:960-977

[2] Imai E, et al. Am J Kidney Dis. 2007;50:927-937.

Disclosure of Interests: Keigo Hayashi: None declared, KENEI SADA Speakers bureau: Ken-Ei Sada received speaker honoraria from Chugai., Yosuke ASANO: None declared, Sumie Hiramatsu Asano: None declared, Yuriko Yamamura: None declared, Keiji Ohashi: None declared, Michiko Morishita: None declared, Haruki Watanabe: None declared, Mariko Narazaki: None declared, Yoshinori Matsumoto: None declared, Tomoko Kawabata: None declared, Jun Wada Grant/research support from: Jun Wada received grant support from Astellas, Bayer, Chugai, Daiichi Sankyo, Kissei, Kyowa Hakko Kirin, MSD, Otsuka, Teijin, Torii, Pfizer, Takeda, and Taisho Toyama., Speakers bureau: Jun Wada received speaker honoraria from Astellas, Boehringer Ingelheim, Novartis, and Tanabe Mitsubishi. DOI: 10.1136/annrheumdis-2019-eular.3422

\section{THU0176 COMPARISON OF ADHERENCE TO MONOTHERAPY VERSUS COMBINED THERAPY IN RHEUMATOID ARTHRITIS}

Iván de Jesús Hernández-Galarza, Dionicio Ángel Galarza-Delgado,

Marielva Castro-González, Rita Pineda-Sic, Miguel Angel Villarreal-Alarcón, Octavio Ilizaliturri Guerra, Rodolfo Allan Uriarte Botello. Hospital Universitario "Dr. José Eleuterio González", UANL, Rheumatology, Monterrey, Mexico

Background: Treatment adherence in Rheumatoid Arthritis (RA) patients vary from 30 to $80 \%$ (1). It is important to identify the associated factors to a low adherence, so clinicians can make interventions to obtain better therapeutic results. Adherence to treatment has been described to be affected by several factors, such as access to healthcare facilities, education, socioeconomic status, quality of communication between physician and patient, among others (2). There are no previous studies that investigate if the number of drugs received in RA patients affects this adherence. REPAIR ${ }^{\circledR}$ is a program designed with the purpose of improve data collection and medical practice in our outpatient clinic.

Objectives: To compare the adherence to synthetic Disease-Modifying Antirheumatic Drugs (DMARDs) among RA patients prescribed with monotherapy and combined therapy.

Methods: Cross sectional, observational, comparative study. This study was conducted in the outpatient rheumatology clinic of University Hospital in Monterrey, México. Consecutive patients with RA, were approached during their normal routine rheumatology appointments, in the March 2018 to December 2018 period. They were asked how many days of the last month they forgot or took their DMARDs (self-report). We classified the adherence rate in 2 categories based on the days of the last month they took the indicated medication; adequate: $75 \%-100 \%$ (> 21 days) inadequate $<75 \% \quad(<21$ days). When adherence was inadequate we interrogated about the cause. Data was obtained from REPAIR ${ }^{\circledR}$ (internal electronic patient record). The Kolmogorov Smirnov test was used to determine normal distribution. Categorical variables are expressed as total number and percentage (\%), and numerical variables as median and the 25th-75th percentiles (q25-q75). Chi square and Mann Whitney $U$ test were used to compare groups and considered significant if $p<0.05$. Data was analyzed with the statistical package SPSS version 24 (New York, USA).

Results: A total of 959 patients were included. When comparing adherence to treatment and gender between groups, no statistically significant difference was found. The main cause of inadequate adherence in the monotherapy group was the economic (30.3\%) and own decision in the combined therapy group $(29.1 \%)$.

Table 1:

\begin{tabular}{lccc}
\hline & $\begin{array}{c}\text { Monotherapy } \\
(\mathbf{n}=\mathbf{3 4 6})\end{array}$ & $\begin{array}{c}\text { Combined therapy } \\
(\mathbf{n}=613)\end{array}$ & $\boldsymbol{p}$ \\
\hline Age (years), median (q25-q75) & $54(44-63)$ & $53(43-59)$ & $\mathbf{0 . 0 1 8}$ \\
$\begin{array}{l}\text { Women, } \mathrm{n}(\%) \\
\text { Inadequate adherence to treatment, }\end{array}$ & $317(91.6)$ & $575(93.8)$ & 0.362 \\
$\mathrm{n}(\%)$ & $52(15)$ & $102(16.6)$ & 0.514 \\
$\begin{array}{l}\text { Adequate adherence to treatment, } \\
\mathrm{n}(\%)\end{array}$ & $294(85)$ & $511(83.4)$ & \\
\hline
\end{tabular}

Conclusion: Patients with combined therapy had the same percentage of inadequate adherence as patients with monotherapy. These results may indicate that number of drugs prescribed not necessarily affects adher ence to treatment. The principal causes for an inadequate adherence to treatment were: economic for monotherapy group and own decision fo combined therapy group. However, long-term studies are needed to evaluate the persistence of treatment in these groups of patients.

\section{REFERENCES}

[1] Van den Bemt BJF, Zwikker HE, van den Ende CHM. Medication adherence in patients with rheumatoid arthritis: a critical appraisal of the existing literature. Expert Rev Clin Immunol. 2012;8(4):337-51.

[2] M.F. M. Improving treatment adherence in patients with rheumatoid arthritis: What are the options? Int J Clin Rheumtol [Internet]. 2015;10(5):34556.

Disclosure of Interests: None declared DOI: 10.1136/annrheumdis-2019-eular.7876

\section{THU0177 TREATMENT PATTERNS AMONG PATIENTS WITH RHEUMATOID ARTHRITIS TREATED WITH A BIOLOGIC DISEASE-MODIFYING ANTI-RHEUMATIC DRUG OR JAK INHIBITOR: A NATION-WIDE STUDY IN KOREA}

Min Jung Kim ${ }^{1}$, Anna Shin ${ }^{2}$, Seunghwan Shin², You-Jung $\mathrm{Ha}^{2}$, Yun Jong Lee ${ }^{2}$ Eun Bong Lee 1 , Yeong Wook Song ${ }^{1}$, Eun Ha Kang ${ }^{2}$. 'Seoul National University Hospital, Division of Rheumatology, Department of Internal Medicine, Seoul, Korea, Rep. of (South Korea); ' Seoul National University Bundang Hospital, Division of Rheumatology, Department of Internal Medicine, Seongnam, Korea, Rep. of (South Korea)

Background: Limited data are available on whether patients with rheumatoid arthritis (RA) are treated with conventional disease-modifying antirheumatic drugs (cDMARDs) according to the current recommendations before they initiate biologic DMARDs (bDMARDs) or JAK inhibitors (JAKis).

Objectives: We examined the treatment patterns among Korean RA patients who received bDMARDs or JAKis in a real world setting, using the 2002-2016 Korean National Health Insurance Service database that covers the entire Korean population.

Methods: We identified RA patients who initiated bDMARDs (TNF inhibitor, abatacept, rituximab and tocilizumab) or JAKis (tofacitinib). Their treat ment patterns during 1 year after RA diagnosis (defined as free of any RA diagnosis or any DMARD use for one year before the diagnosis and prior to the initiation of index drugs (bDMARDs or JAKis) were examined regarding: initial CDMARD used, dose and parenteral use of methotrexate (MTX), use and time to combination therapy of cDMARDs, and steroid use. 